\title{
Modification of Microfiltration Membranes with Ultraviolet Radiation to Separate Oil-In-Water Emulsions
}

\author{
Dinar Dilshatovich Fazullin ${ }^{1}$, Gennady Vitalievich Mavrin ${ }^{1}$ \\ ${ }^{1}$ Candidate of Technical Sciences, Associate Professor of the Department of Chemistry and Ecology, Engineering and \\ Construction Department, Naberezhnye Chelny Institute KFU, Kazan Federal University, Russia. \\ Id scopus 56091448500, ORCID 0000-0002-5017-2535 \\ ${ }^{2}$ Candidate of Technical Sciences, Head of the Department of Chemistry and Ecology, Engineering and Construction Department, \\ Naberezhnye Chelny Institute KFU, Kazan Federal University, Russia. \\ Id scopus 56091349400, ORCID 0000-0003-0276-4365
}

\begin{abstract}
Oil traps and sedimentation tanks are used to treat emulsified wastewater containing oil products. Their disadvantages are the duration of the process, insufficient degree of purification. Poorly treated wastewater is subjected to repeated dilution, or stored for a long time in tanks, after which it enters water bodies, which leads to degradation of biocenoses. Based on the foregoing, it is relevant to use high-performance and lowenergy technologies, one of such methods for wastewater treatment is membrane methods. To increase the efficiency of the process of microfiltration of the emulsion, a membrane of cellulose acetate, PTFE and hydrophilic PTFE was treated with UV radiation. As a result, a decrease in the initial mass of the membrane, an increase in the specific productivity with a slight decrease in the delaying ability was revealed. A 1.5fold increase in specific productivity was established for a water-oil emulsion. The retention capacity of the membrane after processing for petroleum products decreased by $8.6 \%$. The retention capacity of membranes with a hydrophobic surface, on the contrary, increases. The calculations determined that after the PTFE membrane treatment, the degree of NP removal from the model oil emulsion increased by $15.2 \%$. The treatment of membranes with UV radiation leads to an increase in the specific productivity of the membranes with a slight decrease in the retention ability for hydrophilic membranes, and leads to an increase in the retention ability of a hydrophobic PTFE membrane.
\end{abstract}

Keywords: Water-Oil Emulsion, Oil Products, Microfiltration, Membranes, Cellulose Acetate, Polytetrafluoroethylene, Ultraviolet Radiation.

\section{INTRODUCTION}

The most important problem for the protection of water bodies is the pollution of wastewater with oil products. Oil refined products, as well as crude oil, which are so widely used in industry and the national economy, getting into atmospheric, industrial and domestic wastewater, enter natural objects, thereby disrupting the course of natural biochemical processes. This causes the degradation of rivers, lakes, seas, groundwater, and also reduces soil fertility. The oil content is standardized for all types of water,
Oil traps and sedimentation tanks are used to treat emulsified wastewater containing oil products. Their disadvantages are the duration of the process, insufficient degree of purification. Poorly treated wastewater is subjected to repeated dilution, or stored for a long time in tanks, after which it enters water bodies, which leads to degradation of biocenoses. Based on the foregoing, it is relevant to use high-performance and lowenergy technologies, one of such methods for wastewater treatment is membrane methods. In membrane separation processes, the characteristics of the liquid separation process deteriorate over time, a layer of poorly soluble salts (reverse osmosis), gel (ultrafiltration, microfiltration) form on the membrane surface - this phenomenon is called concentration polarization. As a result, equipment shutdown and membrane washing with appropriate cleaning solutions are required, in the worst case membrane replacement. In this regard, it is advisable to modify the membranes, in particular, they treat the surface of the membranes with low-temperature plasma [1], microwave radiation [2,3], ultraviolet (UV) radiation [4] and chemical reagents [5-7].

Often, surface treatment with UV radiation is performed to change the surface properties and performance of the membranes. In [8], two different methods were used for the photochemical modification of a polyetherosulfone membrane to increase surface wettability and reduce adsorption contamination. The filtration efficiency of the modified membranes was compared with the characteristics of a commercially available polyetherosulfone membrane and a regenerated cellulose membrane. Modification by UV radiation made it possible to obtain membranes with practically the same wettability as that of a regenerated cellulose membrane; the wettability increased by $30 \%$ compared to the original polyethersulfone membrane. Also, a significant decrease in irreversible adsorption contamination was found in the modified membrane, which led to a constant decrease in the filtrate flow; to the original buffer stream using any modification.

In [9], the authors investigated a method for increasing the hydrophilicity of a polyethylene terephthalate film by exposure to ultraviolet radiation with a power of $1000 \mathrm{~W}$ for a total of 30-40 min. After modification, the contact angle with water of the modified film was reduced to 0 , and the degree of 
water absorption of the modified film was increased from $85 \%$ to $104 \%$. The mechanical and physical properties of the modified film after treatment with ultraviolet radiation did not deteriorate. According to the results of scanning electron microscopy, it was found that the surface of the modified film became rough and polymer particles appeared. Infrared Fourier spectroscopy showed that particles on the surface of the modified films probably include $\mathrm{COOH}$ and $\mathrm{OH}$ groups. $\mathrm{X}$-ray diffraction results showed the formation of crystalline material. Finally, differential scanning calorimetry thermograms showed that the modification process improved the thermal stability of polyethylene terephthalate.

Certainly, knowledge of the basic principles of membrane clogging mechanisms leads to effective measures to prevent congestion becomes premature. As mentioned before, the phenomenon of membrane clogging in all membrane systems occur; But effective and timely repairs and cleanings are desirable guarantees the system during operation. Food preparation system simultaneously with the design. The main unit is refined and designed in accordance with it. What process to use for preparation. It depends a lot on the characteristics and nature of the feed. Despite the specification and analysis. The variety that takes place on the feed, however, is the design of the unit based on the information obtained from pilot experiments. As a general rule, suspended particles, ferrous compounds and other particles that have the ability to form they have a dense gel layer on the membrane, should be removed before contact with the membrane and in the preparation stage. In some cases, compounds such as chlorine may be used to reduce the microbial load of the feed.

Add ozone and peroxides to the feed solution. These compounds are in the pre-preparation stage and before membrane contact must be removed. Otherwise irreparable damage to the membrane will bring.

To inoculate dimethylaminoethyl methacrylate into a membrane from a styrene-butadiene-styrene triblock copolymer (SBS), the authors of [11] used ultraviolet radiation as an initiator of polymerization. It was found that the degree of vaccination depends on the exposure time, dimethylaminoethyl methacrylate concentration and temperature. The authors found that with an increase in the processing time, the moisture capacity of the membrane increased, as in previous works.

As a result of exposure to ultraviolet radiation, according to the authors' research, the roughness of polymer membranes increases, the moisture capacity and the wetting angle increase, at which the mechanical strength of the film does not deteriorate. An increase in the degree of crystallinity of the polymer and the formation on the surface of new compounds including $\mathrm{COOH}$ and $\mathrm{OH}$ groups were also established. In some works, ultraviolet radiation has found application as a polymerization initiator.

Due to the fact that ultraviolet radiation increases the wettability of the membrane surface, which in turn increases the permeability, this method was used to modify microfiltration membranes designed to separate oil-in-water emulsions. The purpose of the work is to intensify the process of separation of water-oil emulsion by treating microfiltration membranes with ultraviolet radiation.

\section{METHODS}

To increase the productivity and degree of separation of oil emulsions, we modified the thin-film microfiltration membranes from polytetrafluoroethylene (PTFE) with UV radiation using a laboratory setup in atmospheric air. As an initial membrane for modification, we used a microfiltration polymer membrane with a diameter of $47 \mathrm{~mm}$ made of PTFE of the Phenex AF0-0514 brand manufactured by Phenomenex with an average pore size of $0.45 \mu \mathrm{m}$, a microfiltered composite membrane made of PTFE with a hydrophilic surface of the MFK-3G brand manufactured AO Vladipor, with a pore size of $0.45 \mu \mathrm{m}$ and a microfiltration thin-film polymer membrane with a diameter of $47 \mathrm{~mm}$ from cellulose acetate with an average pore size of $0.2 \mu \mathrm{m}$, manufactured by AO Vladipor. The processing time for UV radiation ranged from 1 to 30 minutes, in the wavelength range of 280-320 nm and with a UV radiation power of 36 watts.

To establish the effect of UV radiation on the membranes, we measured the mass of the membranes before and after processing with UV radiation using an analytical balance of the CAUW-220D brand.

The moisture capacity of the membranes was determined by wetting the membrane with distilled water and the content of the mass fraction of moisture in $\%$ was determined using an AND ML-50 moisture meter. The principle of thermogravimetric analysis is implemented in the ML-50 moisture analyzer, in which the sample is dried using a halogen lamp and the moisture content (in\%) is determined, as well as other values calculated on the basis of the difference between wet and dry weight.

The main parameters of membrane separation were installed on a laboratory membrane installation. For separation, a $3 \%$ model oil-in-water emulsion was prepared. The emulsion was prepared from distilled water and industrial oil of the I-20 brand by dispersing using a laboratory mixing device at a speed of $2500 \mathrm{rpm}$, sodium dodecyl sulfate was used as a surfactant. The concentration of oil products in the initial model emulsion was more than $32 \mathrm{~g} / \mathrm{dm}^{3}$. In the process of membrane separation of the emulsion, the following parameters were established: operating pressure $0.3-0.35$ $\mathrm{MPa}$, emulsion temperature $23^{\circ} \mathrm{C}$, emulsion salinity $96 \mathrm{mg} /$ $\mathrm{dm}^{3}, \mathrm{pH} 7.2 \mathrm{pH}$.

The oil content in the model emulsion and in the filtrates was determined by IR spectrometry using a KN-3 concentrator. The principle of operation of the device is based on a photometer measuring the optical densities of a solution of oil products, fats and nonionic surfactants in carbon tetrachloride in the infrared region of the spectrum. The concentration of oil products in the emulsion was measured in a two-wave mode. In the first (measuring) channel, a spectral radiation section of $2930 \pm 70 \mathrm{~cm}^{-1}$ is used. In the second channel, a spectral region of $3333 \pm 70 \mathrm{~cm}^{-1}$ is used, in which oil products do not absorb infrared radiation. 
The potentiometric determination of the hydrogen index of water was carried out using an Anion 4100 brand ionomer / $\mathrm{pH}$ meter. The $\mathrm{pH}$ meter was adjusted using three buffer solutions with $\mathrm{pH}=4.01,6.86,9.18$, and 12.3 prepared from standard titers.

\section{RESULTS AND DISCUSSION}

As a result of the effect of UV radiation on the membranes, a decrease in the mass of the membrane was established, the results are presented in table 1.

Table 1. Change in membrane mass after UV irradiation

\begin{tabular}{|c|c|c|c|c|}
\hline \multirow{2}{*}{ Membrane } & \multirow{2}{*}{$\begin{array}{c}\text { UV } \\
\text { treatment } \\
\text { time, min }\end{array}$} & \multicolumn{2}{|c|}{$\begin{array}{l}\text { Mass of the membrane, } \\
\qquad \mathrm{g}\end{array}$} & \multirow{2}{*}{$\begin{array}{c}\text { Weight } \\
\text { reduction } \\
\Delta, \%\end{array}$} \\
\hline & & initial & $\begin{array}{c}\text { after } \\
\text { processing }\end{array}$ & \\
\hline $\begin{array}{c}\text { PTFE - Phenex } \\
\text { AF0-0514 } \\
\text { (hydrophobic } \\
\text { membrane) }\end{array}$ & \multirow{3}{*}{10} & 0,0862 & 0,0856 & 0,7 \\
\hline $\begin{array}{c}\text { PTFEg - MFFK- } \\
\text { 3G (hydrophilic } \\
\text { membrane) }\end{array}$ & & 0,1512 & 0,1487 & 1,7 \\
\hline Cellulose acetate & & 0,1063 & 0,1037 & 2,4 \\
\hline
\end{tabular}

After treating the membranes with UV radiation, a decrease in the mass of the membranes is observed, and the mass of the MFK-3G membrane from PTFE with a hydrophilic surface decreases more intensively than the mass of the membrane with a hydrophobic surface. According to previous studies [2], as a result of processing the membranes with microwave radiation in atmospheric air, the mass of the PTFE membrane decreases to $0.17 \%$. Therefore, the effect of UV radiation on membranes has a more intense effect than microwave radiation, and UV radiation affects a membrane with a hydrophilic surface more strongly. So after processing the UV membrane from cellulose acetate, a decrease in weight of $2.4 \%$ is observed.

Table 2 presents the moisture capacity of the membranes before and after treatment with UV radiation.

Table 2. The effect of UV treatment on the moisture capacity of membranes

\begin{tabular}{|c|c|c|c|}
\hline \multirow{2}{*}{ Membrane } & \multirow{2}{*}{$\begin{array}{c}\text { UV treatment } \\
\text { time, min }\end{array}$} & \multicolumn{2}{|c|}{ Moisture content, $\%$} \\
\cline { 3 - 4 } & & initial & after processing \\
\hline $\begin{array}{c}\text { PTFE - Phenex AF0- } \\
\text { 0514 (hydrophobic } \\
\text { membrane) }\end{array}$ & 10 & 0,6 & 6,0 \\
\hline $\begin{array}{c}\text { PTFEg - MFFK-3G } \\
\text { (hydrophilic } \\
\text { membrane) }\end{array}$ & & 45,8 & 45,4 \\
\hline Cellulose acetate & & 38,9 & 41,5 \\
\hline
\end{tabular}

From the results of the studies, it was found that the treatment with UV radiation increases the moisture capacity of the membrane from PTFE from $0.6 \%$ to $6 \%$, after processing the membrane from hydrophilic PTFE, the moisture capacity changes slightly. Also, an increase in moisture capacity is observed for cellulose acetate membranes. Therefore, UV radiation affects the surface properties of the membranes and leads to an increase in the hydrophilicity of the membranes.

Next, we conducted a study of the specific productivity of the membranes in distilled water and a water-oil emulsion, the results are presented in table 3 .

Table 3. Specific membrane performance

\begin{tabular}{|c|c|c|c|c|}
\hline \multirow{2}{*}{ Membrane } & \multicolumn{2}{|c|}{$\begin{array}{r}\text { For distilled water G, } \\
\mathrm{dm}^{3} / \mathrm{m}^{2} \cdot \mathrm{h}\end{array}$} & $\begin{array}{c}\text { For water-oil emulsion } \\
\mathrm{G}, \mathrm{dm}^{3} / \mathrm{m}^{2} \cdot \mathrm{h}\end{array}$ \\
\cline { 2 - 5 } & initial & $\begin{array}{c}\mathrm{UV} \\
\text { processing }\end{array}$ & initial & $\begin{array}{c}\mathrm{UV} \\
\text { processing }\end{array}$ \\
\hline $\begin{array}{c}\text { PTFE - } \\
\text { Phenex AF0- } \\
\text { 0514 } \\
\text { (hydrophobic } \\
\text { membrane) }\end{array}$ & 4718 & 4838 & 1904 & 2359 \\
\hline $\begin{array}{c}\text { PTFEg- } \\
\text { MFFK-3G } \\
\text { (hydrophilic } \\
\text { membrane) }\end{array}$ & 10294 & 12579 & 2310 & 3904 \\
\hline $\begin{array}{c}\text { Cellulose } \\
\text { acetate }\end{array}$ & 7077 & 7431 & 1530 & 2264 \\
\hline
\end{tabular}

According to table 3, UV-treated PTFE membranes show a high specific productivity compared to untreated membranes. As a result of processing the Phenex AF0-0514 brand UV radiation, the specific productivity of the membrane in distilled water increases 1.02 times, for $3 \%$ of an oil-water emulsion 1.24 times. For a membrane with a hydrophilic surface of the "MFK-3G" brand, the productivity of distilled water increased after treatment with UV radiation by 1.22 times, by $3 \%$ by water-oil emulsion by 1.7 times. UV radiation treatment increases the productivity of a cellulose acetate membrane by distilled water by 1.1 times for $3 \%$ of an oil-water emulsion by 1.5 times. These changes that occur after UV membrane treatment are apparently associated not only with an increase in the pore size of the membrane, but also with a change in the surface properties of the membrane.

The main indicator of the effectiveness of the membranes is the retarding ability of the membranes. The retention capacity of the membranes was determined by the oil content in the initial water-oil emulsion and membrane filtrate. Table 4 presents the retention ability of the original membranes for petroleum products from $3 \%$ water-oil emulsion. 
International Journal of Engineering Research and Technology. ISSN 0974-3154, Volume 13, Number 11 (2020), pp. $3555-3558$

(C) International Research Publication House. https://dx.doi.org/10.37624/IJERT/13.11.2020.3555-3558

Table 4. The retention capacity of the membranes for petroleum products from $3 \%$ water-oil emulsion

\begin{tabular}{|c|c|c|c|}
\hline \multirow{2}{*}{ Membrane } & \multicolumn{2}{|c|}{ The concentration of petroleum products, $\mathrm{mg} / \mathrm{dm}^{3}$} & \multirow{2}{*}{ Holding ability, $\%$} \\
\hline & initial & after separation & \\
\hline \multicolumn{4}{|c|}{ Source membrane } \\
\hline $\begin{array}{l}\text { PTFE - Phenex AF0-0514 } \\
\text { (hydrophobic membrane) }\end{array}$ & \multirow{3}{*}{$\begin{array}{c}32448 \pm \\
3245\end{array}$} & $17328 \pm 1733$ & 46,6 \\
\hline $\begin{array}{c}\text { PTFEg - MFFK-3G } \\
\text { (hydrophilic membrane) }\end{array}$ & & $10496 \pm 1050$ & 67,7 \\
\hline Cellulose acetate & & $337 \pm 33,7$ & 98,9 \\
\hline \multicolumn{4}{|c|}{ Membrane after UV treatment } \\
\hline $\begin{array}{l}\text { PTFE - Phenex AF0-0514 } \\
\text { (hydrophobic membrane) }\end{array}$ & \multirow{3}{*}{$\begin{array}{c}32448 \pm \\
3245\end{array}$} & $14870 \pm 1487$ & 54,2 \\
\hline $\begin{array}{c}\text { PTFEg - MFFK-3G } \\
\text { (hydrophilic membrane) }\end{array}$ & & $11640 \pm 1164$ & 64,1 \\
\hline Cellulose acetate & & $3155 \pm 316$ & 90,3 \\
\hline
\end{tabular}

The retention capacity of oil products from a model $3 \%$ water-oil emulsion is $46.6 \%$ and $67.7 \%$ for the Phenex AF00514 membrane and the hydrophilic MFPK-3G membrane, respectively. The degree of removal of oil products by the hydrophilic membrane from PTFE grade "MFPK-3G" is $21 \%$ higher compared to the Phenex AF0-0514 membrane with the same pore size of $0.45 \mu \mathrm{m}$. Therefore, the hydrophilic surface properties of the membrane increase the retention ability of oil products from the emulsion.

According to table 4, it is obvious that the degree of removal of oil products from the emulsion after processing the hydrophilic membrane "MFK-3G" with UV radiation is reduced by $3.6 \%$, for a cellulose acetate membrane it decreases by $8.6 \%$ than when separated using the original membranes. In the case of UV radiation treatment in the atmosphere of a hydrophobic membrane of the Phenex AF00514 brand, the opposite is observed: an increase in the degree of separation of the emulsion by $7.6 \%$.

\section{SUMMARY}

To increase the productivity and degree of separation of oil emulsions, we modified thin-film and dynamic membranes from cellulose acetate, PTFE, and hydrophilic PTFEg by $\mathrm{UV}$ radiation for 10 minutes.

After treating the membranes with UV radiation, an increase in moisture capacity and specific productivity is observed. This circumstance is associated with a change in the surface properties of the membranes. Also found a decrease in the mass of the membranes.

A decrease in the retention ability of membranes with a hydrophilic surface after UV treatment is established, and the retention ability of membranes with a hydrophobic surface increases.

\section{CONCLUSIONS}

The treatment of membranes with UV radiation leads to an increase in the specific productivity of the membranes with a slight decrease in the retention ability for a hydrophilic membrane and leads to an increase in the retention ability of a hydrophobic membrane from PTFE when oil products are removed from an oil-water emulsion. A method of treating a membrane with UV radiation is used to intensify the process of membrane separation of emulsions.

\section{ACKNOWLEDGEMENTS}

The work is performed according to the Russian Government Program of Competitive Growth of Kazan Federal University. This work was supported by a grant from the President of the Russian Federation for state support of young Russian scientists - candidates of sciences (MK-1107.2019.8).

\section{REFERENCES}

[1] Alekseeva MYu, Galikhanov MF, Dryakhlov VO, Shaikhiev IG, Fazullin DD. The effect of the demulsifier and corona treatment parameters of polysulfonamide membranes on the separation of oilwater emulsions. Water: chemistry and ecology: scientific journal, 2019;1:77-82.

[2] Fazullin DD, Mavrin GV, Shaikhiev IG, Nizameev IR. Stabilization of the dynamic layer of a membrane by microwave radiation. Membranes and membrane technologies. 2019; 9(1):9-18.

[3] Fazullin DD, Gimadieva AM, Mavrin GV, Shaikhiev IG. Microfiltration Membrane Processing from Cellulose Acetate by Microwave Radiation. Vestnik 
International Journal of Engineering Research and Technology. ISSN 0974-3154, Volume 13, Number 11 (2020), pp. $3555-3558$

(C) International Research Publication House. https://dx.doi.org/10.37624/IJERT/13.11.2020.3555-3558

Technologicheskogo Universiteta. 2017;20(24): 159163.

[4] Liskey CW, Liu C, Hamoy MB, inventors; Honeywell UOP LLC, assignee. High permeability polyimide membranes: gas selectivity enhancement through UV treatment. United States patent US 9,308,488. 2016 Apr 12.

[5] Fazullin DD, Mavrin GV. Separation of water-oil emulsions by a composite membrane with a surface layer of cellulose acetate. Chemical and oil and gas engineering. 2019;8:24-28.

[6] Fazullin DD, Mavrin GV, Shaikhiev IG, Nizameev IR. Ultrafiltration of oil-in-water emulsions with a dynamic nylon-polystyrene membrane. Petroleum Chemistry. 2018 Feb 1;58(2):145-51.

[7] Fazullin DD, Mavrin GV. ULTRAFILTRATION OF MODEL «OIL-IN-WATER» EMULSIONS WITH POLYSULFONAMIDE. TURKISH ONLINE JOURNAL OF DESIGN ART AND COMMUNICATION. 2017 Dec 1;7:1643-51.
[8] Pieracci J, Wood DW, Crivello JV, Belfort G. UVassisted graft polymerization of N-vinyl-2pyrrolidinone onto poly (ether sulfone) ultrafiltration membranes: comparison of dip versus immersion modification techniques. Chemistry of materials. 2000 Aug 21;12(8):2123-33.

[9] Li M, Deng T, Liu S, Zhang F, Zhang G. Superhydrophilic surface modification of fabric via coating with nano-TiO2 by UV and alkaline treatment. Applied Surface Science. 2014 Apr 1;297:147-52.

[10] Malaisamy R, Berry D, Holder D, Raskin L, Lepak L, Jones KL. Development of reactive thin film polymer brush membranes to prevent biofouling. Journal of Membrane Science. 2010 Mar 15;350(1-2):361-70.

[11] Yang JM, Jong YJ, Hsu KY. Preparation and properties of SBS-g-DMAEMA copolymer membrane by ultraviolet radiation. Journal of Biomedical Materials Research: An Official Journal of The Society for Biomaterials and The Japanese Society for Biomaterials. 1997 May;35(2):175-80. 